\title{
Effects of Statin Therapy in Patients with Stroke and Atheromatosis
}

\author{
CRISTINA GROSU ${ }^{1}$, ALEXANDRA MASTALERU2*, OTILIA NITA ${ }^{3 *}$, ROXANA GABRIELA COBZARU ${ }^{4}$, CARMEN VALERICA RAPA4, \\ MARIA MAGDALENA LEON-CONSTANTIN2* , ELENA COJ OCARU ${ }^{5}$ \\ ${ }^{1}$ Grigore T. Popa, University of Medicine and Pharmacy, Faculty of Medicine, IIIrd Medical Department, Discipline of Neurology; \\ 16 Universitatii Str., 700115, Iasi, Romania \\ ${ }^{2}$ Grigore T. Popa, University of Medicine and Pharmacy, Faculty of Medicine, Ist Medical Department, Discipline of Medical \\ Semiology; 16 Universitatii Str., 700115, Iasi, Romania \\ ${ }^{3}$ Grigore T. Popa, University of Medicine and Pharmacy, Faculty of Medicine, II ${ }^{\text {nd }}$ Medical Department, Discipline of Diabetes, \\ Nutrition and Metabolic diseases; 16 Universitatii Str., 700115, lasi, Romania \\ ${ }^{4}$ Grigore T. Popa, University of Medicine and Pharmacy, Faculty of Medicine, Department of Preventive Medicine and \\ Interdisciplinarity, Discipline of Microbiology; 16 Universitatii Str., 700115, Iasi, Romania \\ ${ }^{5}$ Grigore T. Popa, University of Medicine and Pharmacy, Faculty of Medicine, II ${ }^{\text {nd }}$ Medical Department, Discipline of Morphopatology; \\ 16 Universitatii Str., 700115, lasi, Romania
}

Recentstudies have shown that as the average life expectancy increases, more people will suffer a stroke in their lives, diminishing their quality of life. Secondary stroke prevention involves reducing the cardiovascular risk factors and administering medication for preventive purposes, where statins play an important role. The purpose of this study is to highlight the correlations of statins dosage with cardiovascular risk factors (atheromatosis, uric acid value, obesity, etc), in stroke patients receiving hypolipidemic treatment with statins.

Keywords: statins, stroke, uric acid, liver enzymes

Stroke is the third cause of morbidity and mortality worldwide, both in Europe and the US, after ischemic heart disease and oncologic pathology [1-3]. Like many other pathologies, stroke results from the interaction between genetic predisposition and environmental factors. Genetic risk factors cannot be changed, while lifestyle consists of behavioural components that can be improved. Unchangeable risk factors for stroke are: age, familial antecedents, race, sex, previous vascular events. The modifying risk factors include: arterial hypertension, diabetes mellitus, atrial fibrillation, asymptomatic carotid atheromatosis, cardiac disease, hypercholesterolemia, obesity, smoking, sedentarism, poor socio-economic condition, drug use or alcohol abuse [4]. Secondary prevention already involves administration of preventive medication (anti-aggregation, hypolipidemic, antihypertensive), depending on aetiology and associated diseases [5-7]. Two very importantrisk factor in the etiology of stroke (both constituted and transient) are atherosclerosis and dyslipidemia [8-10]. Consequently, following the international guidelines in force recommend the use of statins in patients with a history of stroke as a prognostic element with a double action: to lower cholesterol and triglyceride levels and to stabilize carotid or cerebral atheroma plaques $[7,11,12]$. According to the 2016 ACC/AHA blood cholesterol management guidelines, the usage of statins in secondary prevention showed a reduction of $16 \%$ for stroke, of $27 \%$ for nonfatal myocardial infarction and $20 \%$ for mortality from cardiac events [ 13 15].

Excessive and/or long-term use of statins can cause cytotoxicity, hepatic injury or necrosis, kidney damage and myopathy $[16,17]$. Periodically monitoring of hepatic and kidney function, as well as muscular enzymes, are needed to prevent any undesirable effects [18,19]. Besides their effect on muscle liver and kidney, many studies found evidence connecting statins to new-onset of diabetes mellitus, cognitive impairment and haemorrhagic stroke $[20,21]$. However, the existing literature and guidelines suggest that the benefits of statin therapy outweigh any adverse effects or risks [22].

\section{Experimental part}

The purpose of this study is to highlight the correlations between the value of statins and other cardiovascular risk factors (diabetes, atheromatosis, uric acid value) in patients with stroke receiving hypolipidemic therapy with statins as secondary prevention. Also, we monitored the side effects of statins by analyzing the liver enzymes.

In our retrospective study, we included 58 patients with a history of ischemic stroke, hospitalized between 01.0130.09.2018 in the Neurology Department inside the Clinical Rehabilitation Hospital in lasi, Romania. All patients were assessed for anthropometric measurements (age, weight, height, BMI), biochemical analysis: hepatic enzymes, uric acid, glycemia, glycosylated hemoglobin and lipid profile. Doppler cervical ultrasound was also performed at the level of the bilateral common carotid artery for the identification of atheromatosis and its degree, with a Siemens Accuson X300 system using a 7.5 MHz linear probe through a standardized method [23]. Patients with arterial occlusion or embolic stroke were excluded. All subjects before being examined and included were informed of the research method and signed an informed consent. Statistical analysis was performed with SPSS v.18. In interpreting statistical results we considered $p=0.005$ as the reference value for significance, which corresponds to a confidence interval of $95 \%$. Continuous type variables were presented as mean \pm standard deviation.

In our study we had 23 females and 35 males, with mean age $65.9 \pm 13.11$ years. Most patients had a history of elevated blood pressure ( $82.8 \%$ vs.17.2\%) and also presented with atheroma plaques in the carotid artery at the Doppler examination (53.4\% vs.46.5\%). $36.2 \%$ of the 


\begin{tabular}{|c|c|c|c|c|c|}
\hline & AST & ALT & Uric acid & Cholesterol & Triglycerides \\
\hline$\overline{\text { Mean }}$ & 25.5500 & 36.7741 & 4.5569 & 145.7848 & 116.7788 \\
\hline Std. Deviation & 17.78476 & 36.76194 & 1.73366 & 40.45919 & $56.29924^{-}$ \\
\hline Minimum & 11.00 & 10.60 & $1.26^{-}$ & $85.80^{-}$ & 43.40 \\
\hline Maximum & $106.60^{-}$ & $191.60^{\circ}$ & $8.16^{-}$ & $256.00^{-}$ & 302.00 \\
\hline
\end{tabular}

Table 1

BIOLOGICAL ANALYSIS FOR

THE STUDY GROUP

Table 2

TYPES OF STATINS USED IN THE STUDY

Table 3

DOSAGE OF STATINS USED IN THE STUDY

\begin{tabular}{|c|c|c|c|c|c|}
\hline & & Frequency & Percent & $\begin{array}{l}\text { Valid } \\
\text { Percent }\end{array}$ & $\begin{array}{l}\text { Cumulative } \\
\text { Percent }\end{array}$ \\
\hline \multirow{5}{*}{ Valid } & Without & 7 & 12.1 & 12.1 & 12.1 \\
\hline & $10 \mathrm{mg}$ & 22 & 37.9 & 37.9 & 50.0 \\
\hline & $20 \mathrm{mg}$ & 18 & 31.0 & 31.0 & 81.0 \\
\hline & $40 \mathrm{mg}$ & 10 & 17.2 & 17.2 & 98.3 \\
\hline & $80 \mathrm{mg}$ & 1 & 1.7 & 1.7 & 100.0 \\
\hline
\end{tabular}

patients were overweight and $25.8 \%$ were obese. 53 of the patients included associated type 2 diabetes mellitus insulin dependent.

The mean value for AST was $25.5 \pm 17.7 \mathrm{mg} / \mathrm{dL}$, with a maximum of $106 \mathrm{mg} / \mathrm{dL}$, for ALT it was $36.7 \pm 36.7 \mathrm{mg} / \mathrm{dL}$, with a maximum of $191.6 \mathrm{mg} / \mathrm{dL}$, for uric acid the mean value was $4.5 \pm 1.7 \mathrm{mg} / \mathrm{dL}$, with a maximum of $8.16 \mathrm{mg} /$ $\mathrm{dL}$. As for the lipid profile, mean cholesterol was $145.7 \pm 40.4 \mathrm{mg} / \mathrm{dL}$ and for tryglicerides was $116.7 \pm 56.2$ $\mathrm{mg} / \mathrm{dL}$ (table 1).

Most of the study subjects had statins (87.9\%) in the treatment regimen, but there were also patients who did not receive statin therapy at home, even after the cerebrovascular event. Among the statin type, atorvastatin was the most used (69\%), then rosuvastatin (17.2\%) and simvastatin (1.7\%) last (table 2).

Regarding the statin doses used, the most frequent dose was $10 \mathrm{mg}$ (37.9\%), followed by $20 \mathrm{mg}$ (31.0\%), then 40 $\mathrm{mg}(17.2 \%)$ and only $1.7 \%$ of patients were treated with the $80 \mathrm{mg}$ dose (table 3).

\section{Results and discussions}

The international guidelines in place for ischemic stroke mention the need for statins to be used as secondary prevention [13]. In our study, $12 \%$ of patients did not have chronic statin treatment, $37.9 \%$ had statin at the $10 \mathrm{mg}$ dose, $31 \%$ had a statin dose of $20 \mathrm{mg}, 17.2 \%$ had $40 \mathrm{mg}$ of statin and $1.7 \%$ had the statin dose of $80 \mathrm{mg}$. The recommended doses in the European Cardiology Guide are $40 \mathrm{mg}$, respecting $80 \mathrm{mg}$ in patients with a history of stroke [13]. The same guidelines mention the possibility of decreasing the statin dose when the hepatic enzymes increase by 3-5 times the normal value, 3 weeks after initiation of the statin-lipid lowering regimen. In our study, the altered aspartate aminotransferase (AST) value was found in a similar percentage of $1.7 \%$ in patients taking statin of $10 \mathrm{mg}, 20 \mathrm{mg}, 40 \mathrm{mg}$ or $80 \mathrm{mg}$. Note that the statistically significant percentage of patients with increased liver enzymes by $3,4 \%$ in the absence of hypolipidemic therapy (fig. 1). Among hepatic enzymes, we found a statistically significant correlation between the AST value and the statin dose used ( $p=0.039)$.

Another risk factor for vascular disease is the uric acid. In our study, we noticed a statistically significant difference

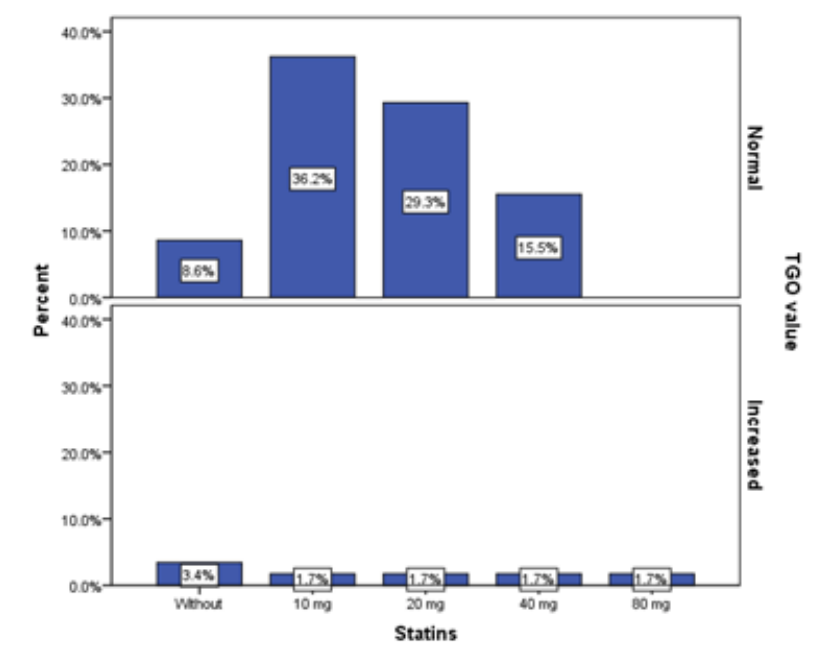

Fig.1 Correlations between dosage of statins and ALT value

between the uric acid value and the statin concentration used. Thus, elevated uric acid was found in $2 \%$ of patients receiving $10 \mathrm{mg}$ statin treatment, the same proportion as patients receiving the $20 \mathrm{mg}$ or $40 \mathrm{mg}$ dose. It should be noted that the uric acid value is not altered when the dyslipidemic treatment is administered at the maximum dose of $80 \mathrm{mg}$. Increased uric acid was quantified in $6 \%$ of patients, decreased in $65.3 \%$ of them and normal in $28.7 \%$. The value of uric acid was taken into account in all patients regardless of whether or not they are taking urate-lowering therapy, so it seems that statins, besides their hypolipidemic role, also have a role in lowering the uric acid, a demonstrated cardiovascular risk factor. The statistically significant difference was observed between the statin dose used versus the normal uric acid value $(p=0.046)$ and the elevated uric acid value (fig. 2).

Statin therapy is absolutely mandatory in patients with a history of stroke, especially if they present with diabetes also. Unfortunately, only $8.5 \%$ of diabetic patients undergoing insulin treatment were also treated with statin and there was a statistically significant difference between statin dose in diabetic patients, respectively, without diabetes $(p=0.003)$. Patients with oral diabetes mellitus did not show any statistically significant correlation between doses of statins used. Although the percentage 


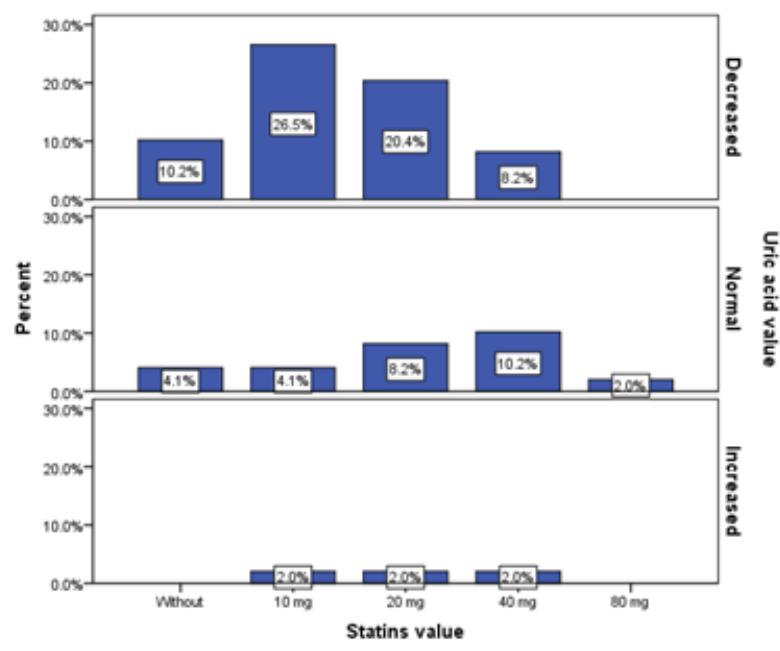

Fig 2. Correlations between statin dose and uric acid value

of diabetic patients receiving dyslipidemic therapy is low, we noticed that most (3.4\%) took the $40 \mathrm{mg}$ dose, statistically significant from the other doses used in our patients. The percentage is similar for the $10 \mathrm{mg}$ and 20 $\mathrm{mg}$ dose. Note that the $80 \mathrm{mg}$ dose is found only in patients with stroke and diabetes, unfortunately in a low percentage of $1.7 \%$ (fig. 3).

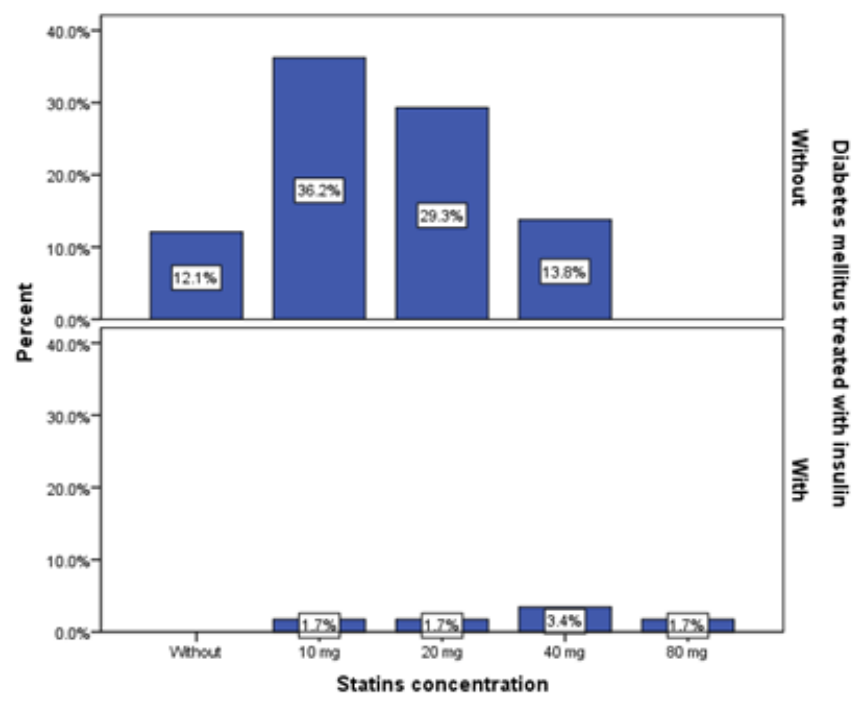

Fig 3. Correlations between statins concentration and presence of diabetes mellitus

According to the recommendations of the international protocols for the secondary prevention management of ischemic stroke patients it is recommended to quantify carotid atheromatosis by cervical Doppler ultrasound. In our study, atheromatosis was found in $53.4 \%$ of patients with ischemic stroke. $8.6 \%$ did not have statin treatment. There was a statistically significant difference between the percentage of patients with atheromatosis and the percentage of patients withoutatheromatosis. For the statin dose of $10 \mathrm{mg}$ and $20 \mathrm{mg}$ respectively, the percentage of patients treated with statin but without atheromatosis was statistically significant compared to atherosclerotic patients (22.4\% vs $15.5 \%$ at the $10 \mathrm{mg}$ dose, respectively $17.2 \%$ vs. $13.8 \%$ at the $20 \mathrm{mg}$ dose). The percentages are reversed with a statistically significant difference in patients with stroke, atheromatosis and $40 \mathrm{mg}$ statin and patients without atheromatosis. The statin dose of $80 \mathrm{mg}$, as recommended by the guidelines, was identified in $1.7 \%$ of stroke patients with established atheromatosis (fig. 4). So,

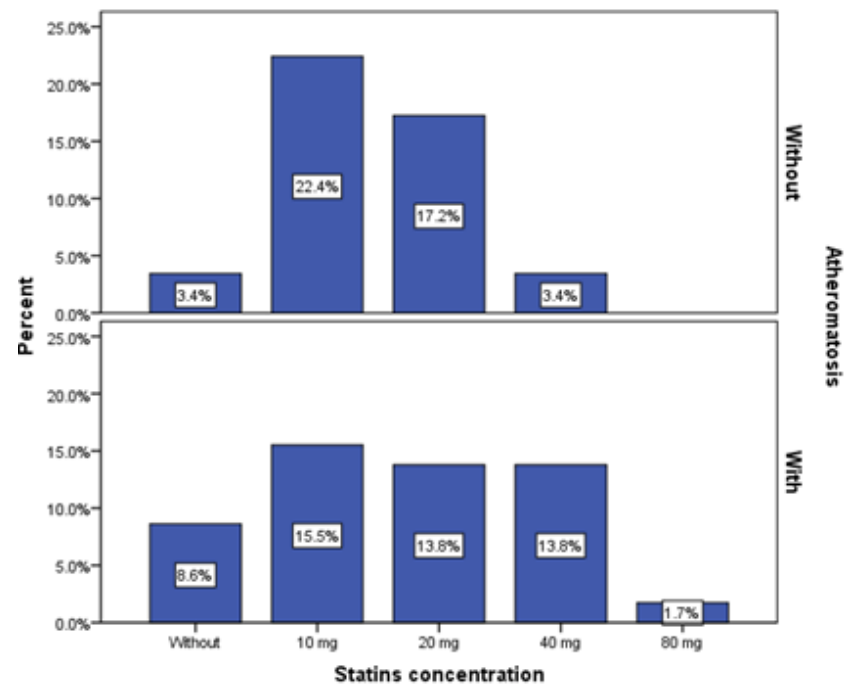

Fig 4. Correlations between statins concentration and atheromatosis

patients with atheromatosis and stroke are treated optimally at a rate of $15.5 \%$. We did not find any statistically significant difference between cholesterol and triglycerides and the statin dose.

\section{Conclusions}

In our study, we found a significant link between atheromatosis and statin treatment, more obvious in patients taking a higher dose. We also found a connection between the statin dose and the decrease of uric acid value, another cardiovascular risk factor. So, it is imperative to use statins to lower cholesterol value and to stabilize the atheroma plaque in patients with stroke.

\section{References}

1.LOPEZAD, MATHERS CD, EZZATI M, JAMISON DT, MURRAY CJ . Global and regional burden of disease and risk factors, 2001: systematic analysis of population health data. Lancet 367, 2006, p. 1747-1757. 2.ROTHWELL PM, COULL AJ, SILVER LE, FAIRHEAD JF, GILES MF, LOVELOCK CE et al. Population-based study of event-rate, incidence, case fatality, and mortality for all acute vascular events in all arterial territories (Oxford Vascular Study). Lancet 366, 2005, p. 1773-1783.

3.WAFA HA, WOLFE CDA, RUDD A, WANG Y. Long-term trends in incidence and risk factors for ischemic stroke subtypes: Prospective population study of the South London Stroke Register. PLoS Med 15, no. 10, 2018, e1002669.

4.SUN Q, CHANG S, Lu S, ZHANG Y, CHANG Y. The Efficacy and Safety of 3 Types of Interventions for Stroke Prevention in Patients With Cardiovascular and Cerebrovascular Diseases: A Network Metaanalysis. Clin Ther. 39, no. 7, 2017, p. 1291-1312.

5.MORTENSEN MB, NORDESTGAARD BG, AFZAL S, FALK E. ACC/AHA guidelines superior to ESC/EAS guidelines for primary prevention with statins in non-diabetic Europeans: the Copenhagen General Population Study. Eur Heart J. 38, 2017, p. 586-594.

6.KERNAN WN. Guidelines for the prevention of stroke in patients with stroke and transient ischemic attack: A guideline for healthcare professionals from the American Heart Association/American Stroke Association. Stroke. 45, 2014, p. 2160-236.

7.AMARENCO P, GOLDSTEIN LB, MESSING M, et al.; SPARCL Investigators, 2009 Relative and cumulative effects of lipid and blood pressure control in the stroke prevention by aggressive reduction in cholesterol levels trial. Stroke. 40, 2009, p. 2486-2492.

8.POLAK JF, SZKLO M, KRONMALI RA, et al. The value of carotid artery plaque and intima-media thickness for incident cardiovascular disease: The Multi-Ethnic Study of Atherosclerosis. J Am Heart Assoc. 2, 2013, p. e000087. 
9.OSAWA K, PEREZ TREJO ME, NAKANISHI R, MCCLELLAND RL, BLAHA MJ, BLANKSTEIN R et al. Coronary artery calcium and carotid artery intima-media thickness for the prediction of stroke and benefit from statins. Eur J Prev Cardiol. 0, no. 0, 2018, p. 1-8.

10.KIM JS, BANG OY. Medical treatment of intracranial atherosclerosis: an update. Stroke. 19, 2017, p. 261-270.

11.ZHONG P, WU D, YE X, WU Y, LI T, TONG S, LIU X. Secondary prevention of major cerebrovascular events with seven different statins: a multi-treatment meta-analysis. Drug Des Devel Ther. 11, 2017, p. 2517-2526.

12.SIRTORI CR. The pharmacology of statins. Pharmacol Res 88, 2014, p. 3-11.

13.PIEPOLI MF, HOES AW, AGEWALL S, ALBUS C, BROTONS C, CATAPANO AL et al. 2016 European Guidelines on cardiovascular disease prevention in clinical practice: The Sixth J oint Task Force of the European Society of Cardiology and Other Societies on Cardiovascular Disease Prevention in Clinical Practice. Eur Heart J. 37, no. 29, 2016, p. 2315-2381.

14.MILLER PE, MARTIN SS. Approach to Statin Use in 2016: an Update, Curr Atheroscler Rep, 18, no. 5, 2016, p.20.

15.AMARENCO P, GOLDSTEIN LB, SZAREK M, SILLESEN H, RUDOLPH $A E$, et al. Effects of intense low-density lipoprotein cholesterol reduction in patients with stroke or transient ischemic attack: The stroke prevention by aggressive reduction in cholesterol levels (SPARCL) trial. Stroke. 38, 2007, p. 3198-204.
16.MANCINI GB, BAKER S, BERGERON J, FITCHETT D, FROHLICH J, GENEST J et al. Diagnosis, prevention, and management of statin adverse effects and intolerance: Canadian Consensus Working Group Update. Can J Cardiol. 32, 2016, p. S35-S65.

17.PREISS D. et al. Risk of incident diabetes with intensive-dose compared with moderate-dose statin therapy: a meta-analysis. JAMA. 305, 2011, p. 2556-2564.

18.ABD TT, JACOBSON TA. Statin-induced myopathy: a review and update. Expert Opin. Drug Saf. 10, 2011, p. 373-387.

19.KARAHALIL B et al. Hepatotoxicity is associated with statins. Arh Hig Rada Toksikol. 68, 2017, p. 254-260.

20.MACH F, RAY KK, WIKLUND O, CORSINI A, CATAPANO AL, BRUCKER $E$ et al. Adverse effects of statin therapy: perception vs. the evidence - focus on glucose homeostasis, cognitive, renal and hepatic function, haemorrhagic stroke and cataract Eur Heart J . 0, 2018, p. 1-18.

21.BETTERIDGE DJ, CARMENA R. The diabetogenic action of statinsmechanisms and clinical implications. Nat Rev Endocrinol. 12, 2016;12:90-110.

22.BELLAOSTA S, CORSINI A. Statin drug interactions and related adverse reactions. Expert Opin. Drug Saf. 11, 2012, p. 933-946.

23.STEIN JH, KORCARZCE, HURST RT, LONN E, KENDALL CB, MOHLER ER et al. ASE Consensus Statement. Use of carotid ultrasound to identify subclinical vascular disease and evaluate cardiovascular disease risk: a consensus statement from the American Society of Echocardiography. J Am Soc Echocardiogr. 21, 2008, p. 93-111.

Manuscript received:19.08.2018 